\title{
Can Document Delivery Compensate for Reduced Serials Holdings? A Life Sciences Library Perspective
}

\section{Janet Hughes}

\begin{abstract}
Access versus ownership is the new dilemma facing most librarians in view of the rising costs of serials and not equally increasing budgets. But, is giving access to articles through document delivery really a viable alternative to journal ownership? The Life Sciences Library at The Pennsylvania State University, University Park, decided to test the viability of using commercial document delivery as compensation for discontinued ownership, as a complement to ownership, and as a supplement to ownership by providing access to cancelled, owned-but-unavailable, or never-owned journals through a commercial document delivery service. This article documents the evolution of that procedure and the results of the project.
\end{abstract}

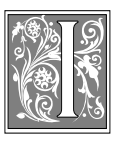

$t$ is a well-known fact in librarianship that the cost of serials, especially science journals, is rising well above the rate of inflation. ${ }^{1}$ However, library materials budgets have not grown concurrently at the same rate and, in fact, have decreased as a percentage of total research university expenditures. ${ }^{2}$ In order to continue to provide maximal access to needed materials, libraries have turned to document delivery, through traditional interlibrary loan (ILL) or commercial document delivery (CDD) services, as a way to supplement collections ${ }^{3}$ or compensate for cancelled serials. ${ }^{4}$

Yet the question of whether access to articles through document delivery is a good alternative to journal ownership remains debatable. Several studies seem to imply that access is a reasonable, if not perfect, alternative, ${ }^{5}$ yet others question that assumption. ${ }^{6}$ One study of performance standards for document delivery concludes that until document delivery is more timely and reliable, access will not replace ownership. ${ }^{7}$ Another paper argues that access cannot serve as a reasonable substitute for current materials, although it might work for older materials. ${ }^{8}$ To resolve this issue, the Life Sciences Library (LSL) at The Pennsylvania State University (Penn State) decided to test the viability of providing access to cancelled, owned-but-unavailable, or never-owned journals through a CDD service.

\section{Background}

The LSL is a subject library within the main library on the largest campus of 
Penn State. Although Penn State has an efficient, centralized ILL service (and one study has suggested that traditional ILL is just as effective and efficient a means of obtaining access to articles as CDD ${ }^{9}$ ) the ILL staff recently have encountered increasing workloads without corresponding increases in personnel. In 1993, impending serials cancellations that would surely increase ILL workloads and perhaps decrease ILL speed and efficiency gave several of the other Penn State subject libraries good reason to test the feasibility of using CDD as a way to improve access to serial publications. That project, conducted in the winter of 1993-1994, found that purchasing articles through CDD was timely and cost-effective. ${ }^{10}$

\section{Articles were requested through the project only if they were from journals recently cancelled or if they were needed urgently for an important paper or grant.}

In the second phase of the project, the LSL was given the opportunity to implement the project. However, there were some differences in the approaches used in this study and the earlier Penn State study. Because other vendors already had been used, the LSL chose to use a supplier not previously tested. A second difference concerned the personnel involved. Most of the branch subject libraries have one or two librarians, so the decision to put a request through the project was limited to one or two people per library. However, the LSL has five librarians, one library assistant, and several clerical staff, as well as many highly trained desk staff. In this study, the LSL allowed any desk personnel, other than student workers, to make the decision to put requests through the project. This meant more training was required, but it decreased the burden of work for any one person. Another difference was that ILL staff were not instructed to pick out re- quests received at the ILL service desk to be included in the project. Because the LSL is in the same building as ILL, it was assumed that all patrons would come to the life sciences desk for life sciences-related ILL requests. The other subject libraries, being in outlying buildings, were more concerned about patrons going to the more central ILL desk. A major difference was that the earlier project was done in anticipation of serials cancellations, whereas the LSL's project occurred after several years of cancellations. Thus, this project used journal cancellation as one of its criteria for putting requests through the project. Finally, the LSL only requested journal articles, whereas the earlier study also had included patents, standards, and conference proceedings, which may have skewed costs.

At the start of the project, the LSL did not use the same restrictions as the other libraries to test the feasibility of using CDD to replace most ILL requests for articles. However, filling all ILL requests through CDD without restrictions proved too costly. Thus, restrictions were added after the first month. Articles were requested through the project only if they were from journals recently cancelled or if they were needed urgently for an important paper or grant. Otherwise, requests were channeled through regular ILL.

The project sought to test how welland at what cost-CDD could fill requests for articles from cancelled journals in order to determine whether CDD was economically feasible as a way to compensate for cancelled journals. It also looked at requests for articles from owned journals that somehow were unavailable to see whether CDD could be used to complement ownership of journals and provide value-added service. Finally, the project wanted to see if CDD could be used to supplement current collections by providing access to urgently needed articles from journals never owned by Penn State. 


\section{Methodology}

In November 1994, the project to test document delivery for access to journals was begun. It was decided that The Genuine Article (TGA) service from the Institute for Scientific Information (ISI) would be the main document provider because its service provided access to most of the desired journals, had reasonable fees, and had not been used in the earlier Penn State study. Also, a study of CDD services had found TGA to have the best turnaround time. ${ }^{11}$ An initial deposit account of $\$ 1,500$ was established, and procedures were put into place.

Actual implementation of the project began on January 31, 1995. At first, any article request brought to the LSL services desk was put through as a document delivery item to be delivered as quickly as possible. However, this inclusive service was very costly and the project was modified after a few weeks. The procedures changed so that document delivery would only be provided if:

1. The LSL had cancelled the journal in the past two years.

2. The item was urgently needed for a grant or thesis deadline.

3 . The item was urgently needed and was owned, but was either missing, at the bindery, or otherwise inaccessible to patrons.

Also, it was decided that the U.S. mail option would be used instead of 24-hour faxing except in cases of extreme need because the turnaround time for regular mail was found to be more cost-effective and a very quick three to five days.

The latter two criteria were included because it was desirable to determine what the cost of giving value-added service would be if everything possible were done to accommodate patrons. In the past, when an owned item was missing due to mutilation, the patron would have to wait for a rush ILL to replace the pages. If the item was off the shelf due to binding, the patron was asked to wait the week or two it would take for the jour- nal to return. If a patron urgently needed an item not owned by the libraries, a rush ILL could be requested but still could take many days. The LSL wanted to investigate the use of CDD to complement ownership of journals by providing this extra level of service.

The LSL faculty, staff, and student workers all were given a basic grounding in the rules and process of the project. It was decided that the project would not be widely publicized to prevent possible abuse of the service, and also because CDD should be transparent to users. ${ }^{12} \mathrm{~Pa}-$ trons completed ordinary ILL request forms and handed them in to the LSL desk staff. However, it was not the staff's responsibility to tell patrons of the service; if the patron indicated urgency or the request fulfilled any of the other criteria, the list of journals available through TGA was checked to see if the item could be obtained through the service.

The identified requests were placed in a designated area that was checked regularly by the clerical staff. The clerical staff would take the request forms, check for errors, confirm that the article could be obtained from TGA, and then phone the request into ISI. The clerical staff also were responsible for receiving the article, calling the patron to inform him or her that the article was available, and doing bookkeeping of statistics and account balances. After patrons had been called, they would then return to the LSL to pick up their articles, which were conveniently placed near the life sciences service desk. In June 1995, the decision was made to continue the project and an additional $\$ 2,300$ was added to the deposit account.

\section{Results}

A total of 120 requests were sent to the CDD service in 1995, of which 112 were filled (93\% fill rate). The eight unfilled requests were either incorrect citations that were later corrected and filled, or were for items for which TGA had a lim- 
ited number of reprints and were no longer available. Had the unfilled rate been higher, the reasons for unfilled requests might have been investigated further, but a 93 percent fill rate was considered high enough to ignore the unfilled requests. An unofficial survey of desk personnel suggested that fewer than a half-dozen requests that came to the LSL's service desk fit the criteria but were known to be unavailable through TGA and thus were forwarded to normal ILL without first being put through the project.

In the first few weeks, most documents were delivered via fax, which gave a twenty-four-hour or less turnaround time. The articles that were mailed usually arrived within three to five days. This turnaround time was considered quite timely, and so after the first few weeks the U.S. mail delivery option was used for all but the most urgent cases.

During the first few weeks' experiment of fulfilling all ILL article requests through document delivery (January 30-February 16, 1995), twenty-two articles were requested at an average cost of $\$ 20$, for a total of $\$ 444.81$. This seemed too costly to continue, so the experiment was reassessed. Beginning in March 1995, an article was requested only if it was from a journal that had been cancelled, if it was of utmost importance for an important paper, thesis, or grant, or if it was unavailable from the collection due to issues missing or being bound. Also, the U.S. mail option was used instead of requesting faxing, which had added a faxing surcharge. After those restrictions were put into place, the number of document requests filled through the project

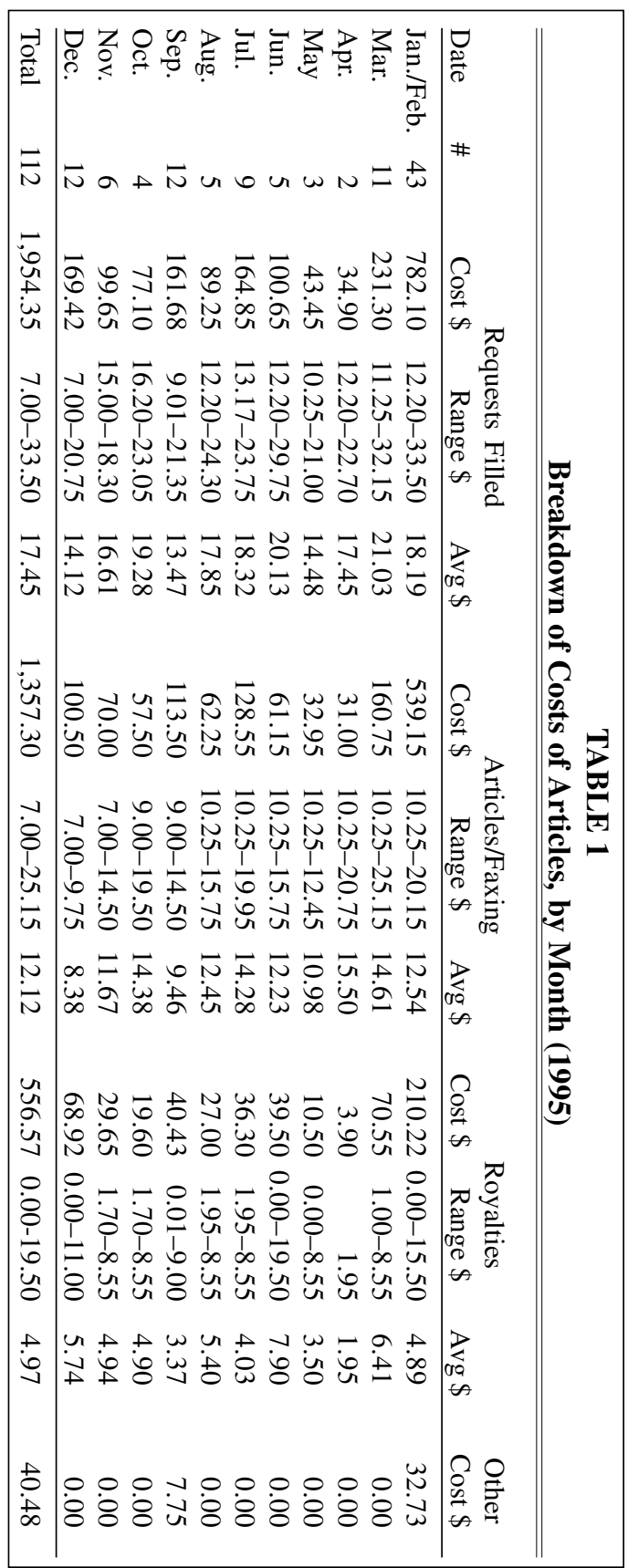


dropped considerably (see table 1 for requests per month in 1995).

The total cost of the 112 articles received was $\$ 1,954.35$. The total cost per article ranged from $\$ 7.00$ to $\$ 33.50$, with an average total cost per article of $\$ 17.45$. Royalty charges ranged from $\$ 0.00$ to $\$ 19.50$ per article, with an average charge of $\$ 4.97$. The costs of the articles' charges and delivery fees ranged from $\$ 7.00$ to $\$ 25.15$, with an average cost of $\$ 12.12$ (see table 1).

After November 1995, a Committee for Institutional Cooperation (CIC) pricing agreement further reduced the average cost of articles to $\$ 7.00$ per article, extended date surcharges to $\$ 6.50$ per request, and changed express delivery charges to $\$ 2.75$ extra for twenty-fourhour fax delivery, $\$ 7.50$ extra for thirtyminute fax delivery, and $\$ 9.00$ for courier delivery. Royalty charges are assessed by the publishers and were not affected by the CIC pricing agreement.

Of the 112 articles received, only nine $(8 \%)$ were from the journals that had been cancelled during the 1993 through 1995 serials cancellations. The nine articles were from a total of six journals, two of which were not LSL journals and had not been paid for with LSL funds. The total cost of the articles from cancelled journals was $\$ 128.95$, whereas the costs of those journals, based on 1994-1995 prices from the thirty-third edition of Ulrich's International Periodicals Directory ${ }_{1}^{13}$ would have been at least $\$ 4,630$ each year. The difference between the costs of the articles and the serials savings for just one year was $\$ 4,501.05$. One journal, Cellular and Molecular Biology, received four requests. It had been cancelled, in part, due to a controversy between editor and publisher that occurred in late 1992.

The cost of supplying articles that were owned, but missing or inaccessible was higher than that of supplying articles from the cancelled journals. There were forty-four requests $(39 \%$ of filled requests) for articles from a total of thirty journals owned by Penn State or available within twenty-four hours via a cooperative agreement with Hershey Medical Center. ${ }^{14}$ The cost of supplying such articles was $\$ 817.51$, with article costs ranging from $\$ 11.25$ to $\$ 26.53$ and averaging $\$ 18.58$. Several owned journals had multiple requests, often for articles from a single volume that probably was at the bindery when the articles were needed.

\section{The cost of supplying articles that were owned, but missing or inaccessible was higher than that of supplying articles from the cancelled journals.}

The cost of supplying articles from journals that were either never owned or cancelled many years ago was the largest part of the project. There were fiftynine article requests, from a total of fiftythree journals never owned by Penn State. The cost of these articles was $\$ 1,007.89$, with article costs ranging from $\$ 9.01$ to $\$ 33.50$ and averaging $\$ 17.08$. Most of these requests (35/59) were made in the first month of the project when all ILLs were put through the project. Afterward, when the restrictions were put into place, the number of requests for never-owned journals filled through the project dropped. The number of requests for never-owned journals channelled through normal ILL was not noted.

Some never-owned journals received more than one request for articles. For example, articles from the Journal of Bone and Mineral Research were requested three times. The ongoing need for this journal by a particular faculty member was already known. Another journal, Journal of Trauma, also received three requests. These requests were made on the same day by one patron for a particular project. It is doubtful that these multiple requests indicate an ongoing need for a subscription to this journal. 
The potential cost of subscribing to all the never-owned journals from which articles were requested would be more than $\$ 17,150$, based on the 1994-1995 Ulrich's. No prices were found for three journals which were given an arbitrary price of $\$ 1$ each.

The time required to process requests was relatively minor. After the procedures had been put into place, the clerical staff in charge of the requests estimated that each request took less than ten minutes to check, phone into ISI, and, upon receipt, inform the patron that the article was available. The bookkeeping of statistics and account balances also was not onerous.

\section{Discussion}

\section{Reliability and Turnaround Time}

As noted in the results, 112 of 120 requests were filled, giving a 93 percent fill rate. However, this fill rate does not take into account items that fit the criteria but were known to be unavailable through TGA and were thus forwarded through normal ILL channels. The fill rate only reflects the reliability of this service to provide items it suggests it should be able to supply. For that criterion, the fill rate was excellent, and so CDD was considered to be a reliable way to gain access to materials known to be available from a particular supplier. The fill rate in this study was considerably higher than that found in another study, in which the researcher found TGA to have difficulty providing items from its current title list. ${ }^{15}$ Reasons for this discrepancy were not investigated but may be due to the nature of the articles requested. The LSL requested mostly scientific articles, which is ISI's specialty, whereas the other study requested articles from all subjects.

The turnaround time, which averaged three to five days using the U.S. mail option, also was considered to be reasonable, especially because quicker, though more expensive, options were available. Thus, the two performance standards that one study thought needed to be improved for access to replace ownership, that is, reliability and turnaround time, ${ }^{16}$ were found to be acceptable in this study.

\section{CDD As Compensation for Cancelled Journals}

Using CDD to compensate for cancelled journals was found to be economically feasible. Similar to the University of Florida's and Southern Illinois University at Carbondale's experiences that cancelled journals only amounted to a minor portion of ILLs, ${ }^{17}$ it was found that only nine requests $(8 \%)$ were for items cancelled in the past few years. However, those studies were comparing requests for cancelled journals against all ILL requests, whereas this study was comparing requests for cancelled journals against only those requests that fulfilled specific criteria. Had all ILL requests continued to be filled through the project, the percentage of requests for cancelled journals to all ILL requests would be much lower. The nine requests were from a total of six cancelled journals, two of which were not LSL journals and had not been paid for with LSL funds. Thus, only four of the 170 LSL journals that had been cancelled between 1993 and 1995 (2\%) received requests for articles.

The cost of compensating for cancelled subscriptions was more than covered by the savings from the journals cancelled. The total cost of the articles from cancelled journals was $\$ 128.95$, whereas the costs of those six journals, based on 19941995 prices from Ulrich's International Periodicals Directory, would have been at least $\$ 4,630$ each year. The difference between the costs of the articles and the serials savings for just one year was $\$ 4,501.05$, a savings of more than 97 percent. This is an underestimation of the total savings because it does not take into account the fact that articles were requested from a range of years and that to retain ownership of these journals would have required several years of 
subscriptions. Moreover, it does not take into account the costs of acquiring, receiving, binding, and storing the issues. Furthermore, if the serial savings from the other 166 LSL journals cancelled between 1993 and 1995 for which there were no article requests also were included, savings that would be in the tens of thousands of dollars, the economic feasibility of using CDD to compensate for cancelled journals becomes very apparent. Another study found that the cost savings for low-use science and math journals could be 91 percent, ${ }^{18}$ which seems in line with these results.

The relative lack of requests for cancelled journals justifies their cancellation. It was noted, however, that as the year progressed, more requests for cancelled journals were made. In fact, there were zero requests for articles from cancelled journals until September 1995. This probably is due to the delay between when a journal is published and when it is indexed or cited elsewhere-that is, when it may come to the attention of researchers. If this is so, more requests for cancelled journals may be expected as time passes. Nevertheless, the difference between one year of subscription costs and the cost for articles from cancelled journals was enough that many more requests for articles could be accepted before the cost savings were depleted. One study revealed that ten or more articles from a particular title would need to be ordered each year before the cost of owning and the cost of acquiring articles on demand become nearly equal. ${ }^{19}$ Only one journal, Cellular and Molecular Biology, came even close with four requests. This journal may be considered for reinstatement, although the four requests were made by one person over two days. The chance that multiple requests will be seen again for this title seems limited. Because this study had found reliability and turnaround time to be good, and because the cost of using CDD to compensate for cancelled journals was found to be economi- cally feasible, using CDD to compensate for cancelled journals was found to be a viable alternative to ownership.

However, there are some reservations about using CDD to compensate for cancelled journals. The journal cancellations the LSL has endured thus far have been relatively minor. There was a certain amount of low-use or peripheral journals that could be discontinued without strongly harming the collections. As more serials cancellations occur, though,

more important or well-used journals in the collection may be affected. At that time, will using CDD to compensate become less acceptable? Even if it is still economically viable to use CDD for journals that are requested up to ten times a year, would this be acceptable in terms of service? Staff time commitments to the project would increase. Also, although patrons usually are willing to wait three to five days for articles from peripheral journals, what would their response be to waiting for access to core titles? The use of CDD to compensate for cancelled journals should be revisited in a few years to determine if it is still a viable alternative to ownership.

In addition, there may be a potential problem with using CDD to compensate for cancelled journals. TGA keeps a rolling five-year supply of articles. Articles from older scientific journals are available, but at a higher cost (\$7.75 extended date surcharge), and such requests cannot be filled as quickly as those for current articles (no twenty-four-hour or less faxing). As time progresses several years past initial cancellation projects, will requests become harder to fill? What guarantee is there that older journal articles 
will be available? Will CDD services be willing to store back issues of journals, or will traditional ILL sources be the only resort for older materials? And will there be traditional ILL sources if many libraries decide to cancel journals and rely on CDD for access? This project received only five requests for extended date articles ( $4 \%$ of filled requests), and only one was for a date earlier than 1990. Scientists tend to use more current information, so perhaps this will not be an issue for science and technology libraries. But what about humanities and social sciences libraries? These questions will need to be addressed in several years' time when more libraries have turned to CDD for access.

\section{CDD to Provide Better Access to Owned Journals}

The cost of providing the value-added service of better access to owned journals proved to be high, $\$ 817.51$, but not excessively so. Requests for owned journals made up 39 percent of filled requests. This seems high when compared to the earlier Penn State study in which approximately 11 percent of requests were for owned titles. ${ }^{20}$ The reasons for journals being unavailable are numerous. Unfortunately, reasons for requests for owned items were not noted. If this study were to be done again, it probably would be useful to note the reasons for unavailability of owned items so that such problems could possibly be corrected or reduced.

Requests may have been made if the issues were available but articles were missing due to mutilation. However, the LSL's mutilation data do not show close correspondence with requests for owned items, and the LSL's mutilation rate has not been noted as being extraordinary. It is possible that issues could have been delayed or never received. Again, though, the LSL's rate of serials delays and nonreceipts was not extraordinary. Thus, mutilation and delays do not explain the difference in rates of requests for owned items between this study and the earlier one.

One reason for the unavailability of owned items would be that they were being bound. Table 2 shows that most requests for owned items came in the first two months, the summer months, and December. There was a problem with the binder in the first few months such that journals sent off for binding were slow to return, and the summer months and December are the times when many journals are sent off for binding because they are intersession times. Thus, the bindery schedule could have been the reason for many of the requests for owned items. However, the other subject libraries follow approximately the same bindery schedule as the LSL, so the discrepancy remains. The differences could have been due to the problems with the binder. However, if percentage of requests for owned items were calculated ignoring the data from the months with problems with the binder (January 31 to March 31, 1995), the percentage would still be 28 , which is high compared to the earlier Penn State study. Thus, the problems with the binder cannot fully explain the discrepancy between the LSL's rate of requests for owned items and that of the earlier study.

A possible explanation for the discrepancy may be the physical layouts of the libraries. Because the LSL is within a much larger library and there is no exit desk at the entrance of the LSL, journals may be used in areas of the main library quite remote from the LSL. It may take days for items used in the other wings of the main library to be reshelved in the LSL, whereas in the subject branch libraries, items are confined to a fairly small area and can be quickly reshelved. Finally, it also is possible that LSL patrons were less willing to accept the unavailability of owned journals and thus more requests were put through, or LSL staff were more lenient in their interpretation of the restrictions. 


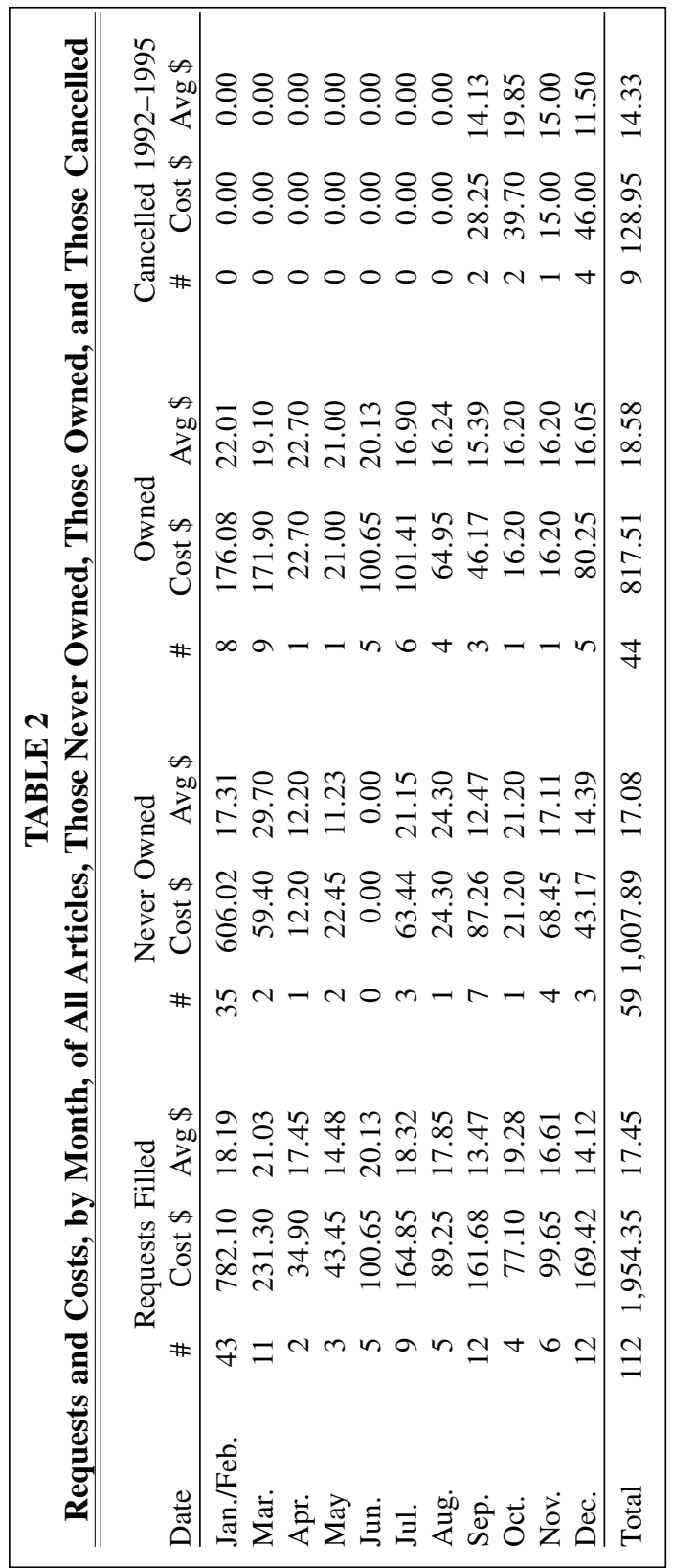

Whatever the reasons for the large number of requests for owned items, it was clear that this value-added service was appreciated by the patrons. Although no formal patron surveys were performed to assess patron satisfaction with the higher level of service, anecdotal evidence suggests that most patrons were pleasantly surprised to find the library willing to take this extra step to accommodate them.

Because the alternative to not providing the added-value service would be that patron needs were not met, the cost of providing this extra level of service seemed reasonable. In times of fiscal restraint, it may not be possible to give value-added service. Whether the goodwill and patron satisfaction generated by the service is sufficient to justify the cost is an administrative judgment and beyond the scope of this study.

\section{CDD to Supplement the \\ Current Collections}

The cost of supplying articles from journals that were either never owned or cancelled many years ago was the largest part of the project. There were fifty-nine such article requests with a total cost of $\$ 1,007.89$. Most of these requests $(35 / 59)$ were made in the first month of the project when all ILLs were put through the project. After the restrictions were put into place, the number of requests for never-owned journals filled through the project dropped considerably.

Even with the restrictions, CDD seemed to work well as a way to supplement the collections. The potential cost of subscribing to all the never-owned 
journals from which articles were requested would be more than $\$ 17,150$, based on the 1994-1995 Ulrich's International Periodicals Directory, with a potential cost savings of 94 percent. Some never-owned journals received more than one request for articles. Articles from the Journal of Bone and Mineral Research were requested three times. This journal has been studied previously as a possible additional subscription due to faculty interest. However, the faculty member who uses this journal the most expressed satisfaction with the CDD option, and so CDD may be continued for this journal rather than obtaining a subscription to it. Another journal, Journal of Trauma, also received three requests. These requests were made on the same day by one patron for a particular project. Because the subject area is not one supported by the LSL, it is not under consideration for subscription. Thus, even with multiple requests for never-owned journals, the fiscal feasibility of using CDD in lieu of new subscriptions seems evident.

If CDD was to be used on a regular basis to supplement the collections while circumventing traditional ILL, as it was before the restrictions were implemented, the number of requests processed would surely increase. The staff hours involved would thus increase dramatically, especially if more detailed bookkeeping and statistics were needed as is the case in normal ILL, with concomitant increases in the cost of the service. It probably would be less feasible as a substitute for traditional ILL unless an organizational shift toward decentralized ILL released more staff and funds. It was unfortunate that the unrestricted part of the project had to be curtailed because it would be useful to see how costly CDD would be when used as a substitute for traditional ILL to supplement the collections, and also how well decentralized ILL would work. Fortunately, the ILL department has gradually migrated to using CDD in conjunction with traditional ILL, so only the question of whether decentralized ILL would work better remains.

\section{Conclusions}

This project was designed to test how well-and at what cost-CDD could fill requests for articles from cancelled life sciences journals and to see whether CDD was economically feasible as a way to compensate for cancelled journals. The choices made for journal cancellation were reinforced by the low percentage of articles requested from cancelled journals. For those few requests, CDD was found to be a very cost-effective and timely way to compensate for cancelled journals. TGA was found to be a reliable supplier of life sciences articles. The only reservations about using CDD as a way to compensate for cancelled journals are questions about the future. As cancellations affect more core journals, will CDD still be viable, and will there be sufficient access to older materials in the future?

The project also looked at requests for articles from owned journals that somehow were unavailable to see whether CDD could be used to provide valueadded service. Higher-than-expected need for this value-added service revealed a need for the Life Sciences Library to examine possible reasons why journals that should be available somehow are not. Whatever the reasons for the unavailability of owned journals, CDD was found to be a useful complement to ownership. Patrons generally appreciated the extra effort, and again, the effort was timely, reliable, and not overly expensive. However, the question of whether it is cost-effective to provide extra service in times of fiscal restraint was not addressed and should be examined at the administrative level.

Finally, the project was designed to determine whether CDD could be used to supplement the current collections by providing access to urgently needed articles from journals never owned by Penn 
State. Extending the collection by using CDD as an alternative to ownership proved beneficial. Subscriptions for the journals from which articles were requested would have been expensive, and most were requested only once, indicating that they were of peripheral need. Even for the journals requested more than once, CDD offered a cost-effective and timely alternative to ownership.

Commercial document delivery was found to be a viable way to compensate for cancelled journals, to complement the existing collections, and to supplement the collections; and for the Life Sciences Library at Penn State, access is indeed a viable alternative to ownership of some journals.

\section{Notes}

1. Bruce C. Bennion, "Why the Science Journal Crisis?" Bulletin of the American Society for Information Science 20 (Feb./Mar. 1994): 25-26.

2. Anthony M. Cummings, Marcia L. Witte, William G. Bowen, Laura O. Lazarus, and Richard H. Ekman, in University Libraries and Scholarly Communication : A Study Prepared for The Andrew W. Mellon Foundation (Washington, D.C.: ARL, 1992), 39.

3. Tina E. Chrzastowski and Mary A. Anthes, "Seeking the 99\% Chemistry Library: Extending the Serial Collection through the Use of Decentralized Document Delivery," Library Acquisitions: Practice \& Theory 19 (summer 1995): 141-52; Anthony W. Ferguson and Kathleen Kehoe, "Access vs. Ownership: What Is Most Cost-Effective in the Sciences?" Journal of Library Administration 19, no. 2 (1993): 89-99.

4. Thomas L. Kilpatrick and Barbara G. Preece, "Serials Cuts and Interlibrary Loan: Filling the Gaps," Interlending \& Document Supply 24, no. 1 (1996): 12-20.

5. Ferguson and Kehoe, "Access vs. Ownership," 98; Kilpatrick and Preece, "Serials Cuts and Interlibrary Loan," 19.

6. Cheryl B. Truesdell, "Is Access a Viable Alternative to Ownership? A Review of Access Performance," Journal of Academic Librarianship 20 (Sept. 1994): 200-206; Maurice B. Line, "Access versus Ownership: How Real an Alternative Is It?" IFLA Journal 22, no. 1 (1996): 35-41.

7. Truesdell, "Is Access a Viable Alternative to Ownership?" 205.

8. Line, "Access versus Ownership," 40.

9. Kathleen Kurosman and Barbara A. Durniak, "Document Delivery: A Comparison of Commercial Document Suppliers and Interlibrary Loan Services," College \& Research Libraries 55 (Mar. 1994): 129-39.

10. Elaine Clement, "A Pilot Project to Investigate Commercial Document Suppliers," Library Acquisitions: Practice \& Theory 20 (summer 1996): 137-46.

11. Wayne Pedersen and David Gregory, "Interlibrary Loan and Commercial Document Supply: Finding the Right Fit," Journal of Academic Librarianship 20 (Nov. 1994): 263-72.

12. Bill Coons and Peter McDonald, "Implications of Commercial Document Delivery," College $\mathcal{E}$ Research Libraries News 56 (Oct. 1995): 626-29.

13. Ulrich's International Periodicals Directory, 1994-95, 33rd. ed. (New Providence, N.J.: R. R. Bowker, 1994).

14. For details of this cooperative agreement, see Esther Y. Dell and Nancy I. Henry , "A Resource Sharing Project Using Ariel Technology," Medical Reference Services Quarterly 12 (spring 1993): 17-27.

15. Alice D. Mancini, “Evaluating Commercial Document Suppliers: Improving Access to Current Journal Literature," College E Research Libraries 57 (Mar. 1996): 123-31.

16. Truesdell, "Is Access a Viable Alternative to Ownership," 205.

17. Michele J. Crump and LeiLani Freund, "Serials Cancellations and Interlibrary Loan: The Link and What It Reveals," Serials Review 21 (summer 1995): 29-36; Kilpatrick and Preece, "Serials Cuts and Interlibrary Loan," 16.

18. Eleanor A. Gossen and Suzanne Irving, “Ownership versus Access and Low-Use Periodical Titles," Library Resources and Technical Services 39 (Jan. 1995): 41-52.

19. Ferguson and Kehoe, "Access vs. Ownership," 92.

20. Clement, "A Pilot Project to Investigate Commercial Document Suppliers," 140. 